\title{
Synthesis and characterization of $M_{3} V_{2} O_{8}(M=C a, S r$ and $B a)$ by a solid-state metathesis approach
}

\author{
PURNENDU PARHI, V MANIVANNAN*, SANDEEP KOHLI ${ }^{\dagger}$ and PATRICK McCURDY ${ }^{\dagger}$ \\ Department of Mechanical Engineering, ${ }^{\dagger}$ Department of Chemistry, Colorado State University, Fort Collins, \\ CO 80523, USA
}

MS received 24 January 2008; revised 14 February 2008

\begin{abstract}
A solid-state metathesis approach initiated by microwave energy has been successfully applied for the synthesis of orthovanadates, $\mathrm{M}_{3} \mathrm{~V}_{2} \mathrm{O}_{8}(\mathrm{M}=\mathrm{Ca}, \mathrm{Sr}$, and $\mathrm{Ba})$. The structural, vibrational, thermal, optical and chemical properties of synthesized powders are determined by powder $\mathrm{X}$-ray diffraction, scanning electron microscopy, X-ray photoelectron spectroscopy, Fourier transform infrared spectroscopy, differential scanning calorimetry, magnetic property measurements and diffused reflectance spectra in the UV-VIS range. The direct bandgap of the synthesized materials was found to be $3.55 \pm 0.2 \mathrm{eV}, 3.75 \pm 0.2 \mathrm{eV}$ and $3.57 \pm 0.2 \mathrm{eV}$ for $\mathrm{Ca}_{3} \mathrm{~V}_{2} \mathrm{O}_{8}, \mathrm{Sr}_{3} \mathrm{~V}_{2} \mathrm{O}_{8}$ and $\mathrm{Ba}_{3} \mathrm{~V}_{2} \mathrm{O}_{8}$, respectively.
\end{abstract}

Keywords. Ceramics; chemical synthesis; X-ray microscopy; optical properties; magnetic properties.

\section{Introduction}

Many hosts for rare earth ions comprising ternary calciumoxo-metallates have been studied and $\mathrm{CaWO}_{4}$ is one among them investigated extensively (Brixner and Flournoy 1985). In this regard, the alkaline earth metal orthovanadates, $\mathrm{M}_{3} \mathrm{~V}_{2} \mathrm{O}_{8}(\mathrm{M}=$ divalent metal $)$, have attracted a lot of attention due to their interesting transport, ferroelectric properties, and use in solid-state lasers (Grzechnik and McMillan 1997a,b; Merkle et al 1992; Buijsse et al 1995; Zhuravlev and Fotiev 1980). In addition such orthovanadates have found potential usage in television tubes, luminescent lamp coatings and flat panel displays, to name a few.

Among many metal orthovanadates, divalent $\mathrm{Ca}, \mathrm{Sr}$ and $\mathrm{Ba}$ vanadates are of particular interest. For example, calcium orthovanadate, $\mathrm{Ca}_{3} \mathrm{~V}_{2} \mathrm{O}_{8}$, belongs to a distorted variant of the $\mathrm{K}_{2} \mathrm{~Pb}\left(\mathrm{SO}_{4}\right)_{2}$ palmierite structure. It is made up of $\left[\mathrm{M}\left(\mathrm{XO}_{4}\right)_{2}\right]^{4-}$ layers $[\mathrm{M}=$ divalent atom, $\mathrm{X}=$ pentavalent atom] linked by $\mathrm{M}^{2+}$ cations where the oxygen atoms form a hexagonal close packing. The interlayer site for the $\mathrm{Ca}^{2+}$ cation is half occupied with a random distribution of vacancies. The defect structure along with the presence of $\mathrm{V}^{4+}$ ions accounts for its high temperature ferroelectric $\left[T_{\mathrm{c}} \sim 1373 \mathrm{~K}\right]$ and high electronic conductivity (Glass et al 1978; Grzechnik 2002).

Strontium and barium orthovanadates, $\mathrm{Sr}_{3} \mathrm{~V}_{2} \mathrm{O}_{8}$ and $\mathrm{Ba}_{3} \mathrm{~V}_{2} \mathrm{O}_{8}$, exhibit intense rare earth activated luminescence and when optimized will have intensity of lumine-

\footnotetext{
*Author for correspondence (mani@engr.colostate.edu)
}

scence approaching that of commercially used $\mathrm{YVO}_{4}$ rare-earth materials (Grzechnik and McMillan 1997a). In addition, near IR-laser action for $\mathrm{Sr}_{3} \mathrm{~V}_{2} \mathrm{O}_{8}$ and $\mathrm{Ba}_{3} \mathrm{~V}_{2} \mathrm{O}_{8}$ doped with $\mathrm{Mn}^{5+}$ at $1168 \mathrm{~nm}$, and $1170 \mathrm{~nm}$ have been reported (Merkle et al 1992; Buijsse et al 1995). Also, barium orthovanadate, due to excellent microwave dielectric properties have been studied for use as microwave filters and antennas (Umemura et al 2006).

In general, these important orthovanadates have been synthesized by solid-state reaction using different precursors at high temperatures. The first report of synthesis of $\mathrm{Ca}_{3} \mathrm{~V}_{2} \mathrm{O}_{8}$ was carried out by Tammann in 1925 reacting $\mathrm{CaO}$ and $\mathrm{V}_{2} \mathrm{O}_{5}$ (Tammann 1925). Grzechnik and McMillan (1997b) synthesized $\mathrm{Sr}_{3} \mathrm{~V}_{2} \mathrm{O}_{8}$ and $\mathrm{Ba}_{3} \mathrm{~V}_{2} \mathrm{O}_{8}$ by reacting $\mathrm{SrCO}_{3} / \mathrm{BaCO}_{3}$ and $\mathrm{V}_{2} \mathrm{O}_{5}$ at $1373 \mathrm{~K}$ for $72 \mathrm{~h}$. Simner et al (2000) synthesized $\mathrm{Sr}_{3} \mathrm{~V}_{2} \mathrm{O}_{8}$ by reacting $\mathrm{SrCO}_{3}$ and $\mathrm{V}_{2} \mathrm{O}_{5}$ at $1423 \mathrm{~K}$ for $4 \mathrm{~h}$. Grzechnik and McMillan (1997b) have synthesized $\mathrm{Sr}_{3} \mathrm{~V}_{2} \mathrm{O}_{8}$ particles at $1100^{\circ} \mathrm{C}$ for $72 \mathrm{~h}$. Umemura et al (2006) synthesized barium orthovanadate by calcining the precursors at $700^{\circ} \mathrm{C}$ for $20 \mathrm{~h}$ followed by further sintering at high temperature with sintering aid additives. A combustion process followed by post calcination of the products was followed by Zhang et al (2006) to produce crystals of $\mathrm{Eu}$ doped strontium orthovanadates. These reactions have multi-steps towards product formation and have long reaction times. Therefore, a simplified process that takes less time, and produces crystalline products with high yield is needed.

The solid-state metathesis (SSM) approach is emerging as a viable alternative way of synthesizing inorganic materials of technological importance (Bonneau et al 1991). This approach has advantages over the other traditional 
synthetic methods in terms of reaction rate, with little or no need for external energy. The high lattice energy of the coproduced salt (e.g. $\mathrm{NaCl}$ ) makes the reaction feasible (Panda et al 2003). Previous work by Kaner, Gopalakrishnan, and Parkin has established the versatility of the SSM method to synthesize various inorganic materials including metal pnictides, chalcogenides, carbides, silicides, and borides (Bonneau et al 1991; Treece et al 1994; Rao et al 1995; Gillan and Kaner 1996; Nartowski et al 1999; Gopalakrishnan et al 2000; Panda et al 2003; Mandal and Gopalakrishnan 2005). Metathesis reaction can be initiated by several external sources among which the reactions initiated by microwave radiation are very attractive, since it enables the product formation in a shorter duration of time without generating any residual wastes. Ramanan et al have synthesized biologically active hydroxyapatite using the microwave mediated solid-state metathetic route (Parhi et al 2004, 2006). We have extended such an approach to synthesize several oxide materials (Parhi et al 2008).

The objective of this work is to synthesize orthovanadates of technological importance by a convenient route in contrast to methods commonly found in current literature. Accordingly we have applied the metathesis approach initiated by microwave energy to obtain the desired products. Such an approach to synthesize orthovanadates has not been reported previously. The key advantage with such an approach is that the overall thermal energy associated in the synthesis is less, and the reactions are featured with high yield, easy scalability, and controlled morphology for the final products. We have also determined the optical bandgap of the orthovanadates which has not been reported previously.

\section{Experimental}

$\mathrm{Na}_{3} \mathrm{VO}_{4}, \mathrm{CaCl}_{2} \cdot 2 \mathrm{H}_{2} \mathrm{O}, \mathrm{SrCl}_{2} \cdot 6 \mathrm{H}_{2} \mathrm{O}$ and $\mathrm{BaCl}_{2} \cdot 2 \mathrm{H}_{2} \mathrm{O}$ obtained from Alfa Aesar, USA, were employed for the preparation of the title compounds. Preparation of $\mathrm{Ca}_{3} \mathrm{~V}_{2} \mathrm{O}_{8}$ was carried out by reacting $\mathrm{CaCl}_{2} \cdot 2 \mathrm{H}_{2} \mathrm{O}$ and $\mathrm{Na}_{3} \mathrm{VO}_{4}$ in powder form using a domestic microwave oven $(2.45 \mathrm{GHz}$, $1100 \mathrm{~W}$ power) for $10 \mathrm{~min}$ in the solid-state. The product was washed with water and ethanol and dried at $80^{\circ} \mathrm{C}$ in an oven. Similar synthetic routes are employed for the synthesis of $\mathrm{Sr}_{3} \mathrm{~V}_{2} \mathrm{O}_{8}$ and $\mathrm{Ba}_{3} \mathrm{~V}_{3} \mathrm{O}_{8}$ starting from $\mathrm{Na}_{3} \mathrm{VO}_{4}$ and hydrated $\mathrm{MCl}_{2}(\mathrm{M}=\mathrm{Sr}, \mathrm{Ba})$.

Powder X-ray diffraction (XRD) measurements were carried out using Scintag X2 diffractometer with $\mathrm{CuK}_{\alpha}$ radiation. A scan rate of 1 degree/min with a step size of $0.02^{\circ}$ was employed to obtain the XRD spectra. Search match analysis was performed using Bruker EVA software. Thermogravimetric analysis (TGA) was performed using the weight and temperature calibrated TA Instruments 2950. The sample was heated in a platinum pan with a heating rate of $10^{\circ} \mathrm{C} / \mathrm{min}$ in order to reach the final temperature. Scanning electron microscopic (SEM) characterization was performed on the JSM-6500F, a field emission system, with the In-Lens Thermal Field Emission Electron Gun. Diffuse reflectance (DR) spectra were recorded in the wavelength range $250-2500 \mathrm{~nm}$ using Varian Associates 500 double beam spectrophotometer equipped with a Praying Mantis. Compressed polytetrafluoroethylene was used for standard calibration (100\% reflectance). X-ray photoelectron spectroscopy (XPS) experiments were performed on a Physical Electronics 5800 spectrometer. This system has a monochromatic $\mathrm{AlK}_{\alpha} \mathrm{X}$-ray source $\left(h_{\alpha}=1486 \cdot 6 \mathrm{eV}\right)$, hemispherical analyser, and a multichannel detector. A low energy $(30 \mathrm{eV})$ electron gun was used for charge neutralization on the non-conducting samples. The binding energy (BE) scales for the samples were referenced to the $\mathrm{C} 1 s$ peak at $284.8 \mathrm{eV}$. Differential scanning calorimetry (DSC) was carried out using TA instruments DSC 2920. The samples were hermetically sealed in aluminum pans and heated to the desired temperature at a ramp rate of $10^{\circ} \mathrm{C} / \mathrm{min}$.

\section{Results and discussion}

\subsection{Synthesis of orthovanadates}

Figure 1 shows $\mathrm{XRD}$ of the product when $\mathrm{MCl}_{2} \cdot x \mathrm{H}_{2} \mathrm{O}$ $(\mathrm{M}=\mathrm{Ca}, \mathrm{Sr}, \mathrm{Ba})$ reacted with $\mathrm{Na}_{3} \mathrm{VO}_{4}$ by solid-state metathesis route as per the reaction,

$$
\begin{aligned}
\left(3 \mathrm{CaCl}_{2} \cdot 2 \mathrm{H}_{2} \mathrm{O}+2 \mathrm{Na}_{3} \mathrm{VO}_{4} \stackrel{\Delta}{\longrightarrow}\right. \\
\left.\mathrm{Ca}_{3} \mathrm{~V}_{2} \mathrm{O}_{8}+6 \mathrm{NaCl}+2 \mathrm{H}_{2} \mathrm{O} \uparrow\right) .
\end{aligned}
$$

Figure la shows XRD of the product before washing, where Nick (marked with $*$ ) coexists with intermediate phases of $\mathrm{M}-\mathrm{V}-\mathrm{O}(\mathrm{M}=\mathrm{Ca}, \mathrm{Sr}, \mathrm{Ba})$ marked with \# (JCPDS Card No. 05-0628). The presence of $\mathrm{NaCl}$ confirmed the reaction to have proceeded in a metathetic pathway for all the three vanadates, as established in the literature (Bonneau et al 1991). The as-synthesized products were washed with water and ethanol to remove the $\mathrm{NaCl}$ byproduct and the XRD was taken again. XRD showed an amorphous nature for calcium vanadate, a combination of $\mathrm{Ba}_{3} \mathrm{~V}_{2} \mathrm{O}_{8}$ (major phase) and $\mathrm{Ba}_{4} \mathrm{~V}_{2} \mathrm{O}_{9}$ for barium vanadate, and a combination of $\mathrm{Sr}_{3} \mathrm{~V}_{2} \mathrm{O}_{8}$ (major phase), $\mathrm{Sr}_{2} \mathrm{~V}_{2} \mathrm{O}_{7}$ and $\mathrm{SrV}_{2} \mathrm{O}_{4}$ phases for the corresponding strontium vanadate. In order to find the crystallization temperature for the Ca sample, the sample was subjected to DSC which showed an endothermic peak at $550^{\circ} \mathrm{C}$ (figure 2). XRD of the sample after DSC as well as a small quantity of the sample subjected to $550^{\circ} \mathrm{C}$ for $5 \mathrm{~h}$ in a furnace showed well-crystalline phase formation of $\mathrm{Ca}_{3} \mathrm{~V}_{2} \mathrm{O}_{8}$. $\mathrm{Ba}$ and $\mathrm{Sr}$ samples were subjected to high temperature heating to find out single-phase formation conditions, which was determined to be $800^{\circ} \mathrm{C}$ for $3 \mathrm{~h}$. Figures $1 \mathrm{~b}, \mathrm{c}$ and d showed well-crystalline phases of $\mathrm{Ca}_{3} \mathrm{~V}_{2} \mathrm{O}_{8}, \mathrm{Sr}_{3} \mathrm{~V}_{2} \mathrm{O}_{8}$, and $\mathrm{Ba}_{3} \mathrm{~V}_{2} \mathrm{O}_{8}$, 
respectively in comparison with JCPDS reference patterns (JCPDS Card No. 46-756, 81-1844, 71-2060). Small quantities of impurities were noticed. All the three vanadate phases crystallized in the trigonal system. $\mathrm{Ca}_{3} \mathrm{~V}_{2} \mathrm{O}_{8}$ crystallized in the $R 3 c$ space group whereas the other two vanadates crystallized in $R-3 \mathrm{~m}$ space group.

In order to understand the influence of various vanadate precursors in the formation of orthovanadates, reactions of hydrated $\mathrm{MCl}_{2}(\mathrm{M}=\mathrm{Ca}, \mathrm{Sr}$ and $\mathrm{Ba})$ with ammonium vanadate $\left(\mathrm{NH}_{4} \mathrm{VO}_{3}\right)$ and sodium vanadate $\left(\mathrm{NaVO}_{3}\right)$ have

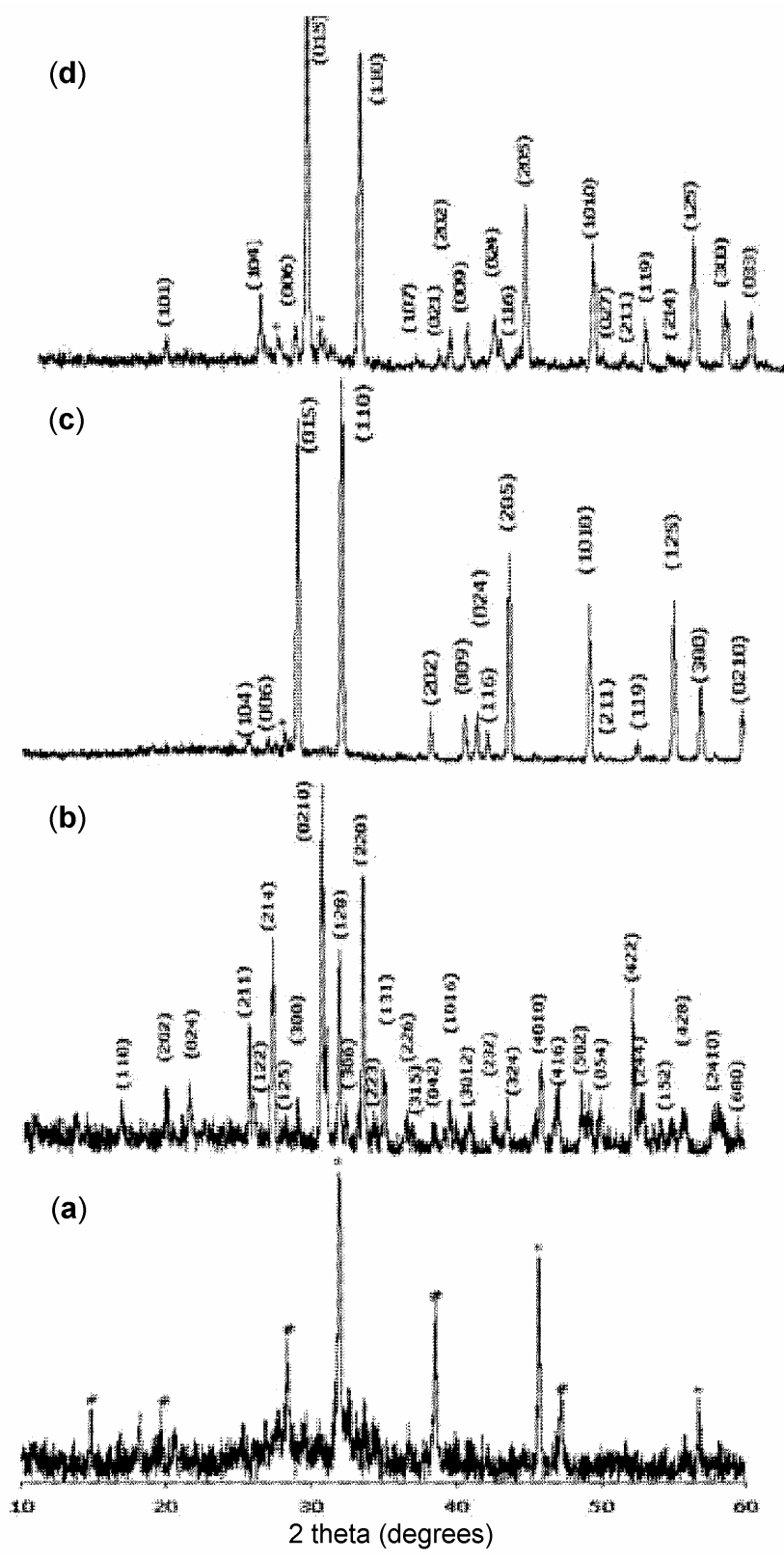

Figure 1. Powder XRD pattern of product before washing, where * corresponds to phases belonging to $\mathrm{NaCl}$ confirming the metathesis nature of reactions. Figures $1 \mathrm{~b}, \mathrm{c}$ and $\mathrm{d}$ correspond to XRDs of crystalline $\mathrm{Ca}_{3} \mathrm{~V}_{2} \mathrm{O}_{8}, \mathrm{Sr}_{3} \mathrm{~V}_{2} \mathrm{O}_{8}$ and $\mathrm{Ba}_{3} \mathrm{~V}_{2} \mathrm{O}_{8}$, respectively. been attempted. XRD of the sample showed no reaction between hydrated $\mathrm{MCl}_{2}(\mathrm{M}=\mathrm{Ca}$, Sr and $\mathrm{Ba})$ with either of the precursors. Changing the reaction conditions within the limitations of the domestic microwave (power, reaction time) as well as performing the reaction in solution metathetic pathway (i.e. subjecting the homogeneous solutions of individual precursors in solution) did not yield the desired product formation.

\subsection{Characterization of orthovanadates}

Figure 3 shows the SEM morphology of the synthesized $\mathrm{M}_{3} \mathrm{~V}_{2} \mathrm{O}_{8}$. SEM showed well defined morphology for all orthovanadates reported in this work. EDX analysis (not shown) confirmed the stoichiometry of the materials. The FTIR spectrum of the $\mathrm{Ca}_{3} \mathrm{~V}_{2} \mathrm{O}_{8}$ sample is shown in figure 4 . The large isolated absorbable peak around $820 \mathrm{~cm}^{-1}$ reveals a typical spectral characteristic of $\mathrm{VO}_{4}^{3-}$ with strong IR absorbable band in the range $780-920 \mathrm{~cm}^{-1}$. The isolated peaks, which contribute to the uniform regular $\mathrm{VO}_{4}$ tetrahedron, prove the orthovanadate nature of $\mathrm{VO}_{4}$. Other weak frequencies in the absorbed peaks that appeared in the ranges $3300-3500$ and $1600-1650 \mathrm{~cm}^{-1}$ are assigned to $\mathrm{O}-\mathrm{H}$ bonds, which are attributed to surface absorbed water.

XPS (figure 5) was used to probe chemical bonding states of the elements in the range $0-1200 \mathrm{eV}$. In the spectra of $\mathrm{Ca}_{3} \mathrm{~V}_{2} \mathrm{O}_{8}$ (figure $5 \mathrm{a}$ ), we can see peaks corresponding to $\mathrm{V} 2 s(628.26 \mathrm{eV}), \quad \mathrm{V} 2 p(516.26 \mathrm{eV}), \quad \mathrm{V} 3 s$ $(68.26 \mathrm{eV}), \mathrm{V} 3 p(41.86 \mathrm{eV}), \mathrm{Ca} 2 s(437.86 \mathrm{eV}), \mathrm{Ca} 2 p$ $(346.66 \mathrm{eV})$ and $\mathrm{O} 1 s(529.6 \mathrm{eV})$. In the case of $\mathrm{Sr}_{3} \mathrm{~V}_{2} \mathrm{O}_{8}$ (figure 5b), peaks corresponding to different atoms are as follows: V2s $(629.2 \mathrm{eV}), \mathrm{V} 2 p(518.8 \mathrm{eV}), \mathrm{V} 3 s(69.32 \mathrm{eV})$, $\mathrm{V} 3 p(42.8 \mathrm{eV}), \operatorname{Sr} 3 s(58.0 \mathrm{eV}), \mathrm{Sr} 3 d(135.6 \mathrm{eV}), \mathrm{Sr} 4 s$ $(64.4 \mathrm{eV}), \mathrm{Sr} 4 p(20 \cdot 4)$ and $\mathrm{O} 1 s(532.4 \mathrm{eV})$. In the case of $\mathrm{Ba}_{3} \mathrm{~V}_{2} \mathrm{O}_{8}$ (figure 5c), peaks corresponding to different atoms are as follows: $\mathrm{Ba} 3 p(1062.8 \mathrm{eV}), \mathrm{Ba} 3 d_{3 / 2}(796.4 \mathrm{eV})$, $\mathrm{Ba}_{3} d_{5 / 2}(781.2 \mathrm{eV}), \mathrm{Ba} 4 s(252.4 \mathrm{eV}), \mathrm{Ba} 4 p(178.8 \mathrm{eV})$,

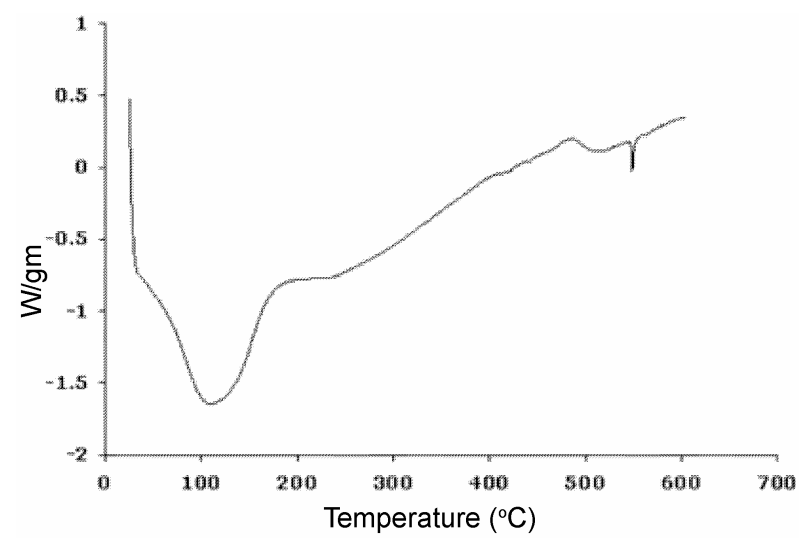

Figure 2. DSC of as-prepared (after washing) $\mathrm{Ca}_{3} \mathrm{~V}_{2} \mathrm{O}_{8}$ sample heated up to $600^{\circ} \mathrm{C}$. 
$\mathrm{Ba} 4 d(90.4 \mathrm{eV}), \quad \mathrm{V} 2 s \quad(628.4 \mathrm{eV}), \quad \mathrm{V} 2 p \quad(517 \mathrm{eV}), \quad \mathrm{V} 3 s$ $(68.4 \mathrm{eV}), \mathrm{V} 3 p(41.2 \mathrm{eV})$ and $\mathrm{O} 1 s(532.1 \mathrm{eV})$. XPS data for all the samples confirmed the oxidation state of vanadium to be in +5 state which is in agreement with the XPS results of single-crystal orthovanadates (Choi et al 2006).

\subsection{Physical property measurements}

Orthovanadates have been extensively used as laseroptics materials, where the bandgap $\left(E_{\mathrm{g}}\right)$ of the material
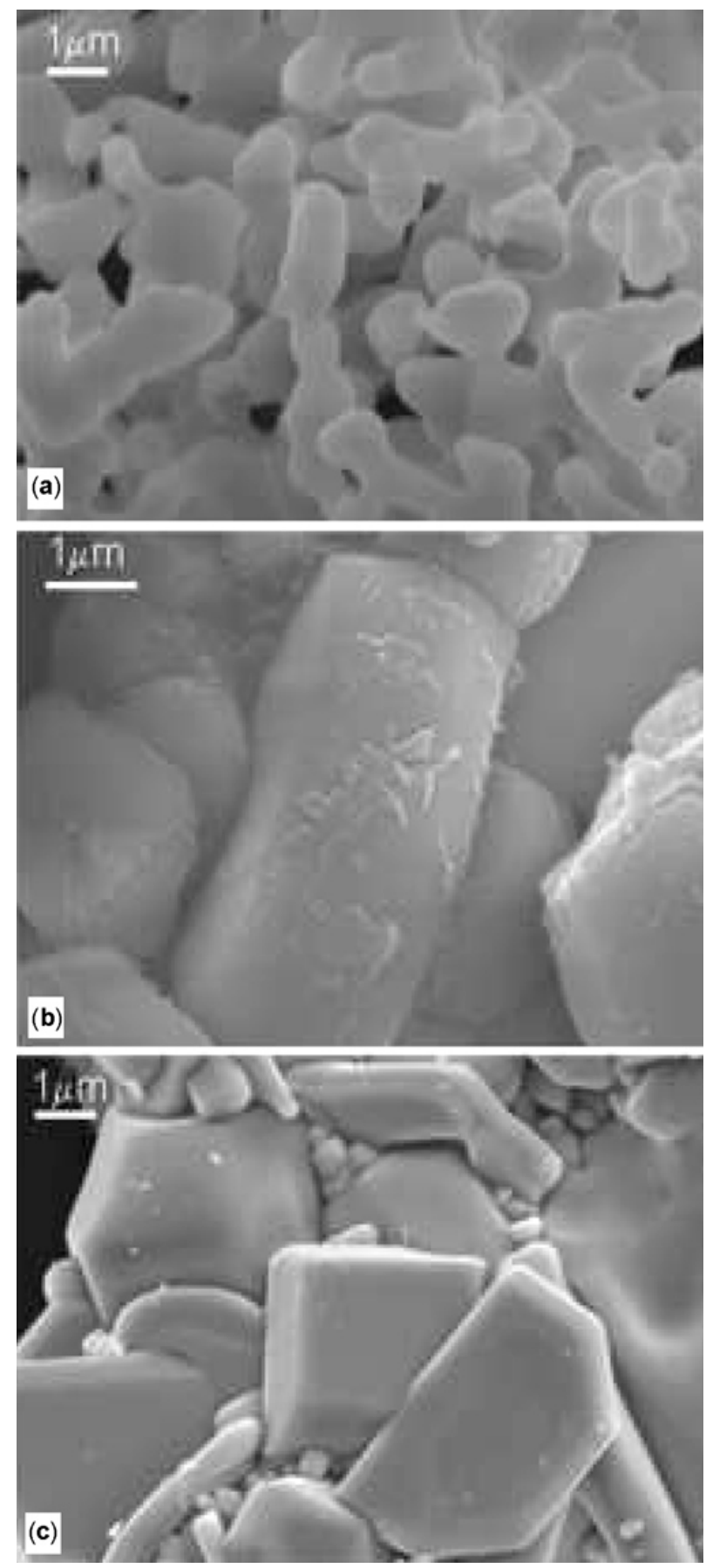

Figure 3. Scanning electron micrograph images of $\left(\right.$ a) $\mathrm{Ca}_{3} \mathrm{~V}_{2} \mathrm{O}_{8}$, (b) $\mathrm{Sr}_{3} \mathrm{~V}_{2} \mathrm{O}_{8}$ and (c) $\mathrm{Ba}_{3} \mathrm{~V}_{2} \mathrm{O}_{8}$ plays an important role in determining its properties. To determine $E_{\mathrm{g}}$ of the orthovanadates diffuse-reflectance measurements were performed. Figure 6 shows the diffuse reflectance spectra of the $\mathrm{M}_{3} \mathrm{~V}_{2} \mathrm{O}_{8}$ sample in the UVVIS-NIR range. The diffuse reflectance data (figure 6a) was used to calculate the absorption coefficient from the Kubelka-Munk (Kubelka and Munk 1931; Kortum 1969) (KM) function defined as

$$
F\left(R_{\infty}\right)=\frac{\alpha}{S}=\frac{\left(1-R_{\infty}\right)^{2}}{2 R_{\infty}},
$$

where

$$
R_{\infty}=\frac{R_{\text {sample }}}{R_{\mathrm{PTFE}}} .
$$

Here $\alpha$ is the absorption coefficient, and $S$ the scattering coefficient and $F\left(R_{\infty}\right)$ the KM function. The energy dependence of the material in the UV-VIS-NIR was further explored. The energy dependence of semiconductors near the absorption edge is expressed as

$$
\alpha E=K\left(E-E_{\mathrm{g}}\right)^{\eta} .
$$

Here $E$ is the incident photon energy $(h v), E_{\mathrm{g}}$ the optical absorption edge energy, $K$ a constant and exponent $\eta$ is dependent on the type of optical transition as a result of photon absorption (Barton et al 1999). The $\eta$ is assigned a value of $1 / 2,3 / 2,2$ and 3 for direct allowed, direct forbidden, indirect allowed and indirect forbidden transition, respectively (Tauc et al 1966). For the diffuse reflectance spectra, the KM function can be used instead of $\alpha$ for estimation of the optical absorption edge energy (Barton et al 1999). It was observed that a plot of $F\left(R_{\infty}\right) E$ vs $E$ was linear near the edge for direct allowed transition $(\eta=1 / 2)$. The intercept of the line on abscissa $\left(F\left(R_{\infty}\right) E=0\right)$ gave the value of optical absorption edge energy as $3.55 \pm 0.2 \mathrm{eV}, \quad 3.75 \pm 0.2 \mathrm{eV}$ and $3.57 \pm 0.2 \mathrm{eV}$ for $\mathrm{Ca}_{3} \mathrm{~V}_{2} \mathrm{O}_{8}, \mathrm{Sr}_{3} \mathrm{~V}_{2} \mathrm{O}_{8}$ and $\mathrm{Ba}_{3} \mathrm{~V}_{2} \mathrm{O}_{8}$, respectively. Figure $6 \mathrm{~b}$

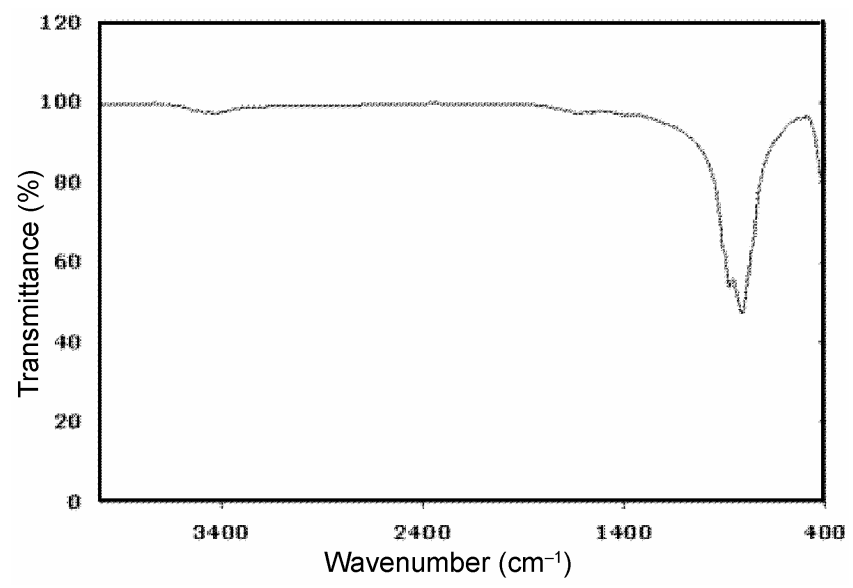

Figure 4. FTIR spectra of $\mathrm{Ca}_{3} \mathrm{~V}_{2} \mathrm{O}_{8}$. 
shows the plot of the same. The diffuse reflectance spectra for direct bandgap orthorhombic $(\beta)$ (Sahu and Kleinman 2004) $\mathrm{Ta}_{2} \mathrm{O}_{5}$ prepared by heating Ta metal in air is also recorded for comparison. The value of optical absorption edge energy for indirect allowed transition for $\mathrm{Ta}_{2} \mathrm{O}_{5}$ was found to be $4 \cdot 0 \pm 0 \cdot 2 \mathrm{eV}$, which is consistent with those seen for the $\beta-\mathrm{Ta}_{2} \mathrm{O}_{5}$ reported earlier (Knausenberger and Tauber 1973). The bandgap values determined showed that the orthovanadates synthesized were likely to show semiconducting behaviour.

Magnetic measurements (magnetic susceptibility $(\chi)$ as a function of temperature) for orthovanadates (figure 7) showed a diamagnetic response for $\mathrm{Ca}_{3} \mathrm{~V}_{2} \mathrm{O}_{8}$ compounds from room temperature to $\sim 50 \mathrm{~K}$ whereas $\mathrm{Ba}$ and $\mathrm{Sr}$ analogs showed a paramagnetic response in the same temperature range. The small upturn below $50 \mathrm{~K}$ is fitted by a Curie-
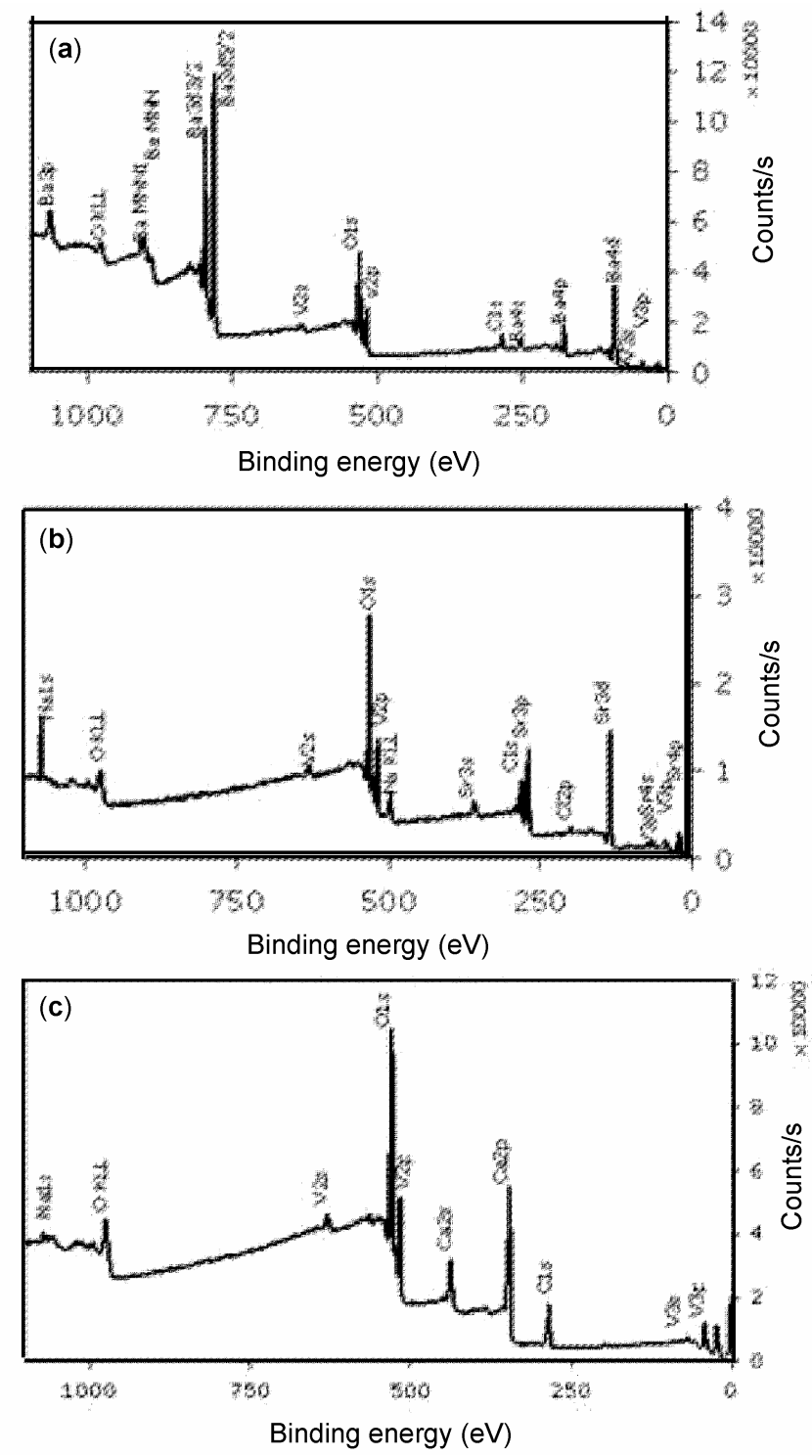

Figure 5. XPS data of (a) $\mathrm{Ca}_{3} \mathrm{~V}_{2} \mathrm{O}_{8}$, (b) $\mathrm{Sr}_{3} \mathrm{~V}_{2} \mathrm{O}_{8}$ and (c) $\mathrm{Ba}_{3} \mathrm{~V}_{2} \mathrm{O}_{8}$.
Weiss expression for $\mathrm{Ca}_{3} \mathrm{~V}_{2} \mathrm{O}_{8}, \mathrm{Ba}_{3} \mathrm{~V}_{2} \mathrm{O}_{8}$ and $\mathrm{Sr}_{3} \mathrm{~V}_{2} \mathrm{O}_{8}$, which suggested the presence of a non-orthovanadate phase with $S=1 / 2$ for all the three vanadates.

\section{Conclusions}

We have successfully synthesized metal vanadates of composition, $\mathrm{M}_{3} \mathrm{~V}_{2} \mathrm{O}_{8}$, where $\mathrm{M}=\mathrm{Ca}$, $\mathrm{Sr}$, and $\mathrm{Ba}$, by a
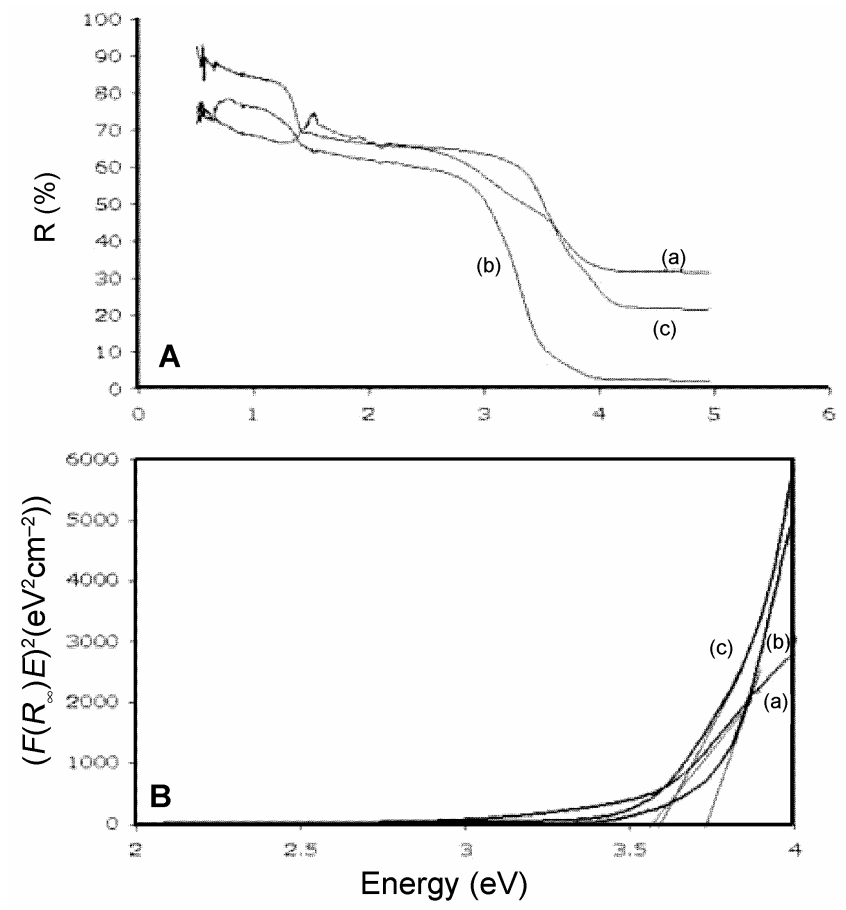

Figure 6. A. Diffuse reflectance spectra of (a) $\mathrm{Ca}_{3} \mathrm{~V}_{2} \mathrm{O}_{8}$, (b) $\mathrm{Sr}_{3} \mathrm{~V}_{2} \mathrm{O}_{8}$ and (c) $\mathrm{Ba}_{3} \mathrm{~V}_{2} \mathrm{O}_{8}$, in the wavelength range $250-$ $2500 \mathrm{~nm}$ and $\mathbf{B}$. plot of $F\left(R_{\infty}\right)$ vs $E(\mathrm{eV})$ for the estimation of the optical absorption edge energy.

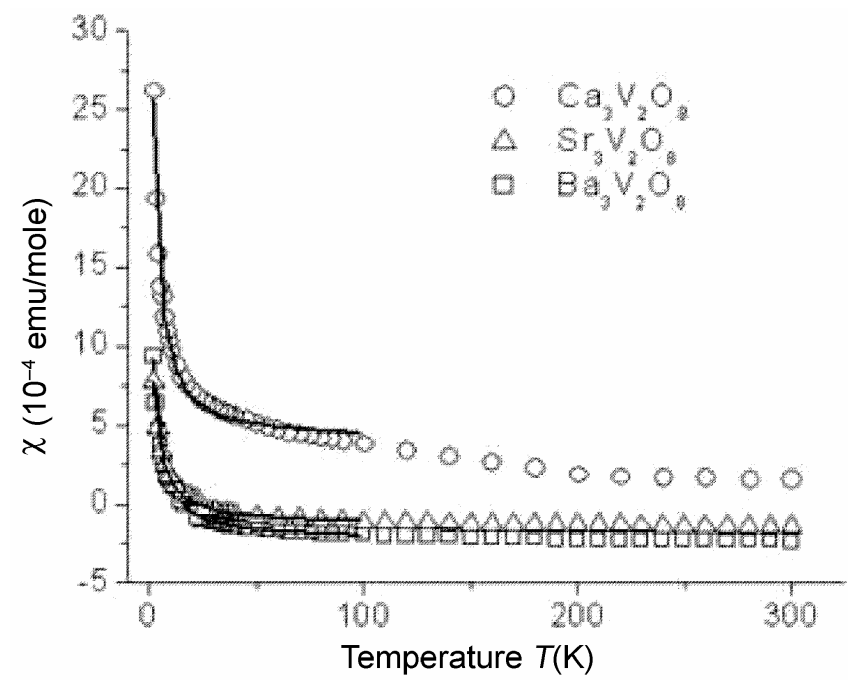

Figure 7. Magnetic susceptibility of $\mathrm{Ca}_{3} \mathrm{~V}_{2} \mathrm{O}_{8}, \mathrm{Sr}_{3} \mathrm{~V}_{2} \mathrm{O}_{8}$ and $\mathrm{Ba}_{3} \mathrm{~V}_{2} \mathrm{O}_{8}$ plotted as a function of temperature. 
solid state metathesis approach driven by microwave energy and studied the structural, magnetic and optical properties. Such a method of synthesis for orthovanadates has not been reported previously. The proposed method has distinct advantages in terms of cost effectiveness, less complexity, scalability, and high yield. Also, the products have well defined morphologies which will enable them to be used for potential applications including luminescent materials, microwave dielectric materials, and laser optic materials.

\section{Acknowledgements}

The authors would like to acknowledge Prof. Allan Kirkpatrick, Department of Mechanical Engineering, CSU, for his continued help, encouragement and support. Thanks are also due to Dr Jaydip Das for help in magnetic measurements.

\section{References}

Barton D G, Shtein M, Wilson R D, Soled S L and Iglesia E 1999 J. Phys. Chem. B103 630

Bonneau P R, Jarvis R F and Kaner R B 1991 Nature 349 510

Brixner L H and Flournoy P A 1985 J. Elect. Chem. Soc. 112 303

Buijsse B, Schmidt J, Chan I Y and Singel D J 1995 Phys. Rev. B51 6215

Choi J G, Ruy M K, Cho C H, Cho D H, Sung N E, Kim J P and Jang M S 2006 Ferroelectrics 33229

Gillan E G and Kaner R B 1996 Chem. Mater. 8333

Glass A M, Abrahams S C, Ballmann A A and Laiacono G 1978 Ferroelectrics 17579
Gopalakrishnan J, Sivakumar T, Ramesha K, Thangadurai V and Subbanna G N 2000 J. Am. Chem. Soc. 1226237

Grzechnik A 2002 Solid State Sci. 4523

Grzechnik A and McMillan P F 1997a J. Solid State Chem. 132 156

Grzechnik A and McMillan P F 1997b Solid State Commun. 102569

Knausenberger W H and Tauber R N 1973 J. Electrochem. Soc. 129927

Kortum G 1969 Reflectance spectroscopy, principles, methods and applications (New York: Springer-Verlag)

Kubelka P and Munk F 1931 Z. Tech. Phys. 12593

Mandal T K and Gopalakrishnan J 2005 Chem. Mater. 172310

Merkle L D, Pinto A, Verdun H and McIntosh B 1992 Appl. Phys. Lett. 612386

Nartowski A M, Parkin I P, MacKenzie M, Craven A J and Macleod I 1999 J. Mater. Chem. 91275

Panda M, Seshadri R and Gopalakrishnan J 2003 Chem. Mater. 151554

Parhi P, Ramanan A and Ray A R 2004 Mater. Lett. 583610

Parhi P, Ramanan A and Ray A R 2006 Mater. Lett. 60218

Parhi P, Manivannan V, Kohli S and McCurdy P 2008 Mater. Res. Bull. (in press)

Rao L, Gillan E G and Kaner R B 1995 J. Mater. Res. 10353

Sahu B R and Kleinman L 2004 Phys. Rev. B69 165202

Simner S P, Hardy J S, Stevenson J W and Armstrong T R 2000 Solid State Ionics 12853

Tammann G 1925 Z. Anorg. U. Allgem. Chem. 14968

Tauc J, Grigorov R and Vancu A 1966 Phys. Status Solidi 15 627

Treece R E, Conklin J A and Kaner R B 1994 Inorg. Chem. 33 5701

Umemura R, Ogawa H, Yokoi A, Ohsato H and Kan A $2006 \mathrm{~J}$. Alloy Compd. $\mathbf{4 2 4} 388$

Zhang H, Lu M, Yang Z, Xiu Z, Zhou G, Wang S, Zhou Y and Wang S 2006 J. Alloy Compd. 426384

Zhuravlev V D and Fotiev A A 1980 Zh. Neorg. Khimii 252560 